\title{
Pathological study of some esophageal lesions of slaughtered sheep in Mosul abattoir
}

\author{
E.K. Al-Hamdany \\ Department of Pathology and Poultry Diseases, College of Veterinary Medicine, University of Mosul, Mosul, Iraq \\ Email: ekalzory@uomosul.edu.iq
}

(Received April 30, 2019; Accepted June 9, 2019)

\begin{abstract}
This study includes collection of 120 samples of sheep esophagus from slaughtered sheep in Mosul abattoir from December 2013 to March 2014 for detection of lesions and their incidence. Total 85 esophagus samples showed lesions from the total collected samples. The revealed lesions included disturbance of cell metabolism manifested by coagulative necrosis, sloughing of epithelial lining the esophagus and vacuolar degeneration at incidence rate 67.7, 23.5 and 17.6\% respectively, circulatory disturbances like petechial, diffuse hemorrhage and edema were noticed at incidence rate $7.05,4.7$ and $3.5 \%$ respectively. Also results showed epithelial hyperplasia, fibroplasia and hyperkeratosis at $47,24.7$ and $31.7 \%$ of the total collected samples respectively, whereas eosinophilic inflammation of esophagus appeared at $3.5 \%$ of collected samples. Jaundice represent the disturbance in pigmentation reported at ratio of $16.4 \%$, also additionally there was parasitic infestation represented by sarcocystosis and worm infestation which impeded in muscularis layer of esophagus at percentage ratio $50.5 \%$ and $3.5 \%$ respectively and a single case of esophageal diverticulosis was recorded at percentage ratio of $1.17 \%$. Section that stained which Masson trichrome stain showed fibroplasia with proliferation of fibroblasts that take a bluish green color between muscle fibers.
\end{abstract}

Keywords: Lesions, Esophagus, Sheep, Sarcosystosis, Esophageal diverticulum Available online at http://www.vetmedmosul.com, (c) 2020, College of Veterinary Medicine, University of Mosul. This is an open access article under the CC BY 4.0 license (http://creativecommons.org/licenses/by/4.0/).

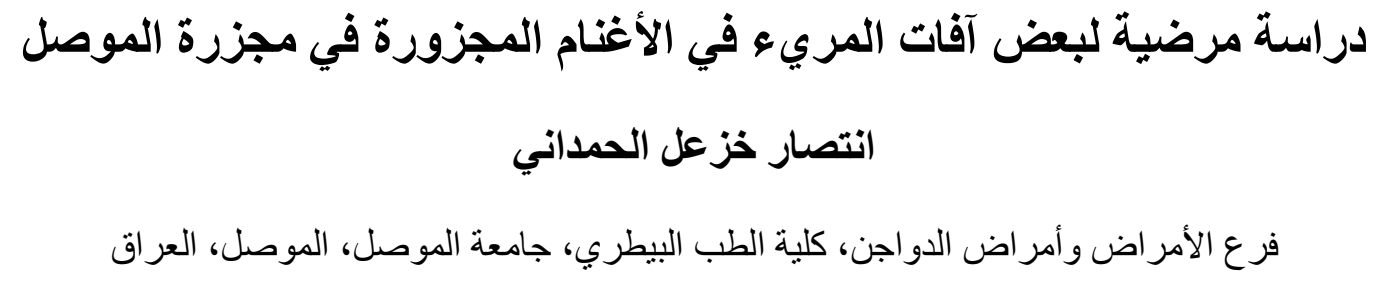

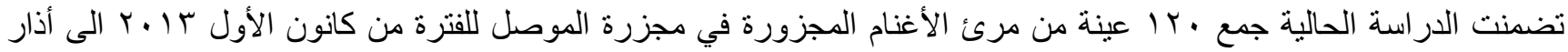

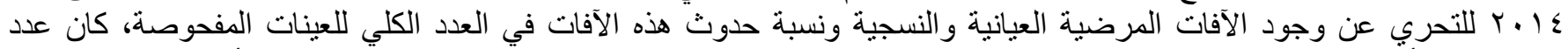

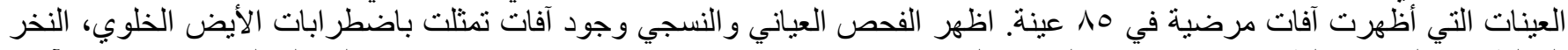

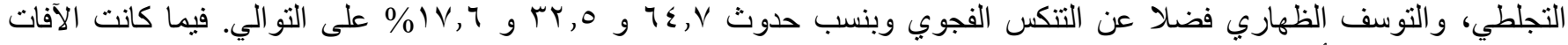

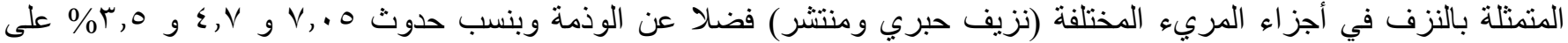

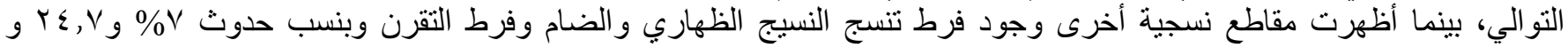

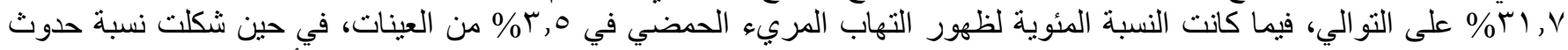

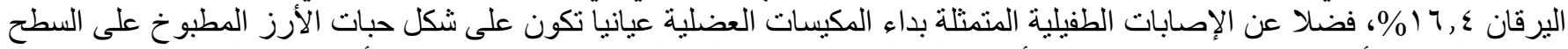

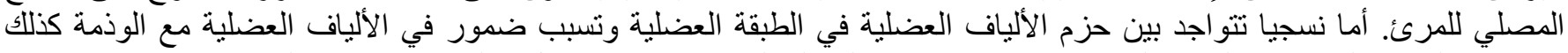

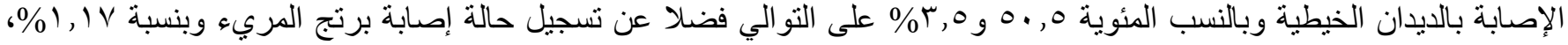




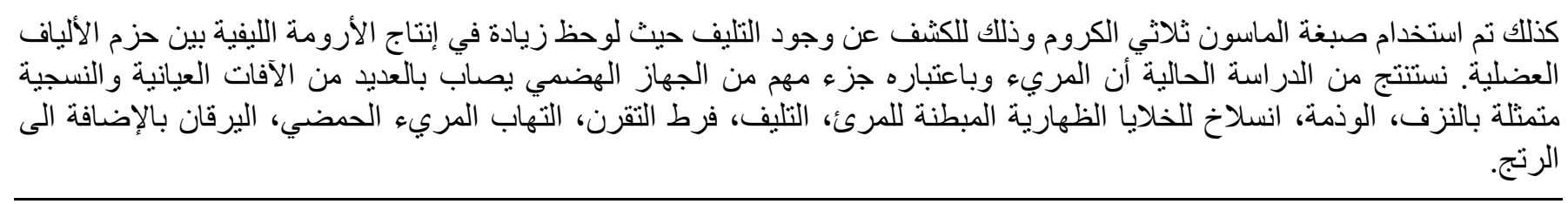

\section{Introduction}

The esophagus is a muscular-membranous tube extending from the oropharynx to the diaphragmatic hiatus. The esophagus begins dorsally to the cartilage of the larynx and extends on the dorsal surface of the trachea up to the level of the second cervical vertebra and then tends to the left side of the trachea and up to the entrance of the chest (1). Function of esophagus is assisted by the digestion of ways to transfer food from the mouth to the stomach and the release of gases by eructation and help in regurgitation, especially in ruminants (2). The esophageal wall is made up of four layers, which are from the outside to the inside; the external layer is the serous layer, then the muscle layer, the subcutaneous layer and the mucous layer, the esophagus is lined by a keratinized stratified squamous epithelium cell (3). There are many lesions that affect the esophagus, including bacterial infections, hyperkeratosis, hyperplasia, mega esophagus $(4,5)$ worms $(6)$, and tumors of squamous cell carcinoma caused by the consumption of bracken fern plant for several weeks will increase incidence of cancer in the digestive tract (7). In addition, wrong use of stomach tube, occurrence of choke when swallowing and regurgitation behavior (2).

This study was designed to report the most important pathological lesions that affect the sheep esophagus with their pathological relevance and classification with documentation of the incidence of these lesions in sheep slaughtered in Mosul abattoir.

\section{Materials and methods}

\section{Sampling}

This study was carried out on the esophagus specimen of sheep received in the Mosul abattoir at age ranged from 2 to 3 years old, started for December 2013 to March 2014. A 120 samples were collected immediately after slaughtered in clean and labeled bags until were reached to the laboratory for the examination.

\section{Fixation and tissue processing}

Samples was examined grossly and noticed lesions were recorded and photographed, the samples then preserved in neutral buffered formalin $10 \%$ for 72 hours at least to conduct a perfect fixation to these tissue sample, then dehydrated by alcohol clearing by xylene, impregnated and embedded in hot paraffin wax, sectioned at 6 microns thickness. Tissue sections stained with routine hematoxylin and eosin stain to demonstrated lesions in sectioned tissues (8), in addition, Masson trichrome stain to detect the presence of collagen fibers (9). The histological section was examined under the light microscope and photographed using digital camera.

\section{Results}

The results of the gross examination showed the presence of lesions in 85 samples from total 120 samples, while the rest of the samples showed no pathological changes. Gross pathological changes characterized by the presence of the congestion on the serosal surface of the esophagus (Figure 1), with the presence of parasites sarcosystis in the form of cooked rice grain at incidence $50.5 \%$ (Figure 2), as well as ecchymosis at percentage $7.05 \%$ (Figure 3 ). A case of esophageal diverticulosis was observed in the percentage of $1.17 \%$ (Figure 4). Some samples showed yellowish discoloration of serous membrane expressing by jaundice with percentage $16.4 \%$.

Histologically the results showed coagulative necrosis at percentage $64.7 \%$, with edema at percentage $3.5 \%$ between muscle fibers in the muscularis (Figures 5 and 6) with vacuolar degeneration at percentage $17.6 \%$,desquamation of epithelial cells lining the esophagus and vacuolar degeneration at percentage $23.5 \%$ and $17.6 \%$ respectively (Figure 7), other tissue sections showed hyperplasia of epithelial cells at percentage $47 \%$ as well as connective tissue hyperplasia at percentage $24.7 \%$ with hyperkeratosis at percentage $31.7 \%$, also hemorrhage at percentage $7.05 \%$ (Figures 8 and 9). Other sections showed esophagitis at percentage $3.5 \%$ represented by infiltration of inflammatory cells specially neutrophils with vasculitis in tunica media was observed (Figure 10), while other sections characterized by the presence of the parasites sarcocystosis in the muscularis with nematodes which found embedded in the muscularis layer and mucosal layer of esophagus (Figure 11). The tissue sections that stained with Masson trichrome showed fibroplasia in the submucosa and a thickening of fibrous tissue between muscle fibers represented by the proliferation of fibroblasts which take a bluish green color (Figures 12-14, Table 1). 
Table 1: Classification and incidence rate of lesions in the infected samples as well as their incidence rate in the total samples studied

\begin{tabular}{llccc}
\hline Type of lesion & \multicolumn{1}{c}{ Classification } & $\begin{array}{c}\text { No. affected } \\
\text { samples }\end{array}$ & $\begin{array}{c}\text { \% lesions in } \\
\text { affected samples }\end{array}$ & $\begin{array}{c}\text { \% lesions in } \\
\text { total samples }\end{array}$ \\
\hline Coagulative necrosis & Disturbance in cell metabolism & 55 & 64.7 & 8.45 \\
Epithelial sloughing & Metabolic disturbance & 20 & 23.5 & 6.16 \\
Vacuolar degeneration & Metabolic disturbance & 15 & 17.6 & 5.12 \\
Petechial hemorrhage & Circulatory disturbance & 6 & 7.05 & 5.00 \\
Diffuse hemorrhage & Circulatory disturbance & 4 & 4.70 & 3.30 \\
Edema & Circulatory disturbance & 3 & 3.50 & 5.20 \\
Esophageal diverticulum & Structural disorder & 1 & 1.17 & 8.00 \\
Epithelial hyperplasia & Cell adaptation & 40 & 47.0 & 33.3 \\
Connective tissue hyperplasia & Cell adaptation & 21 & 24.7 & 17.5 \\
Hyperkeratosis & Cell adaptation & 27 & 31.7 & 22.5 \\
Esophagitis & Inflammation & 3 & 3.50 & 5.20 \\
Jaundice & Pigmentation & 14 & 16.4 & 11.6 \\
Sarcosystosis & Parasitic infections & 43 & 50.5 & 35.5 \\
Nematodiasis & Parasitic infections & 3 & 3.50 & 5.20 \\
\hline
\end{tabular}

Total number of samples examined $=120$, Total number of samples showed pathological lesions $=85$.

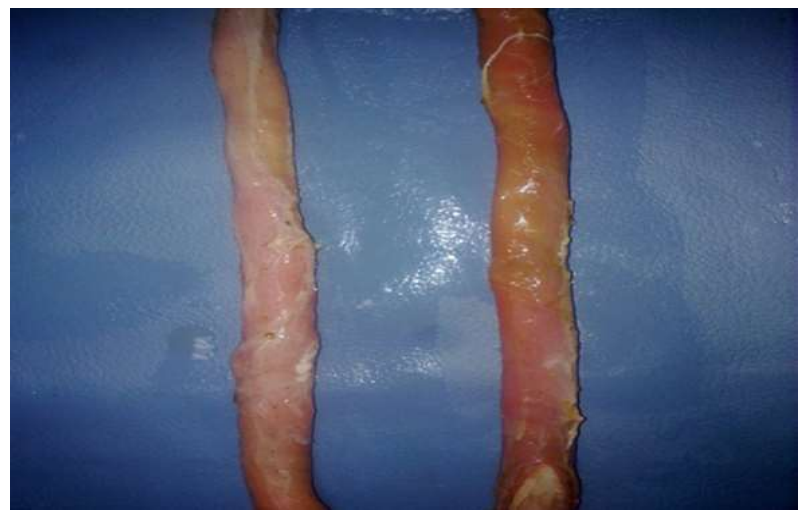

Figure 1: Ovine esophagus showing congestion with normal esophagus in lift side.

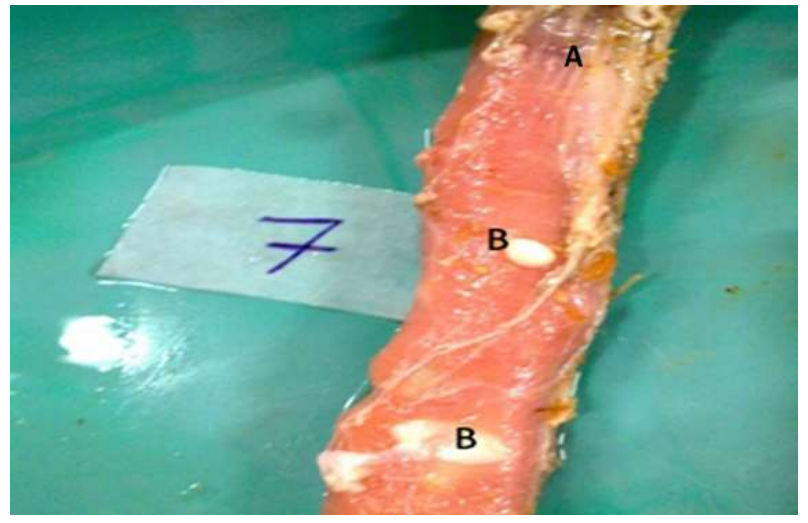

Figure 2: Ovine esophagus showing congestion on serous membrane (A), with parasite sarcosystis (B).

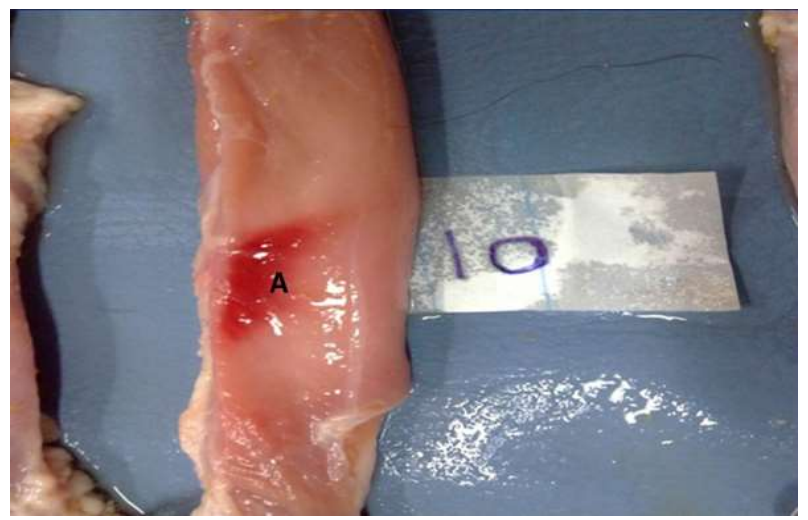

Figure 3: Ovine esophagus showing hemorrhage on serous surface $(\mathrm{A})$.

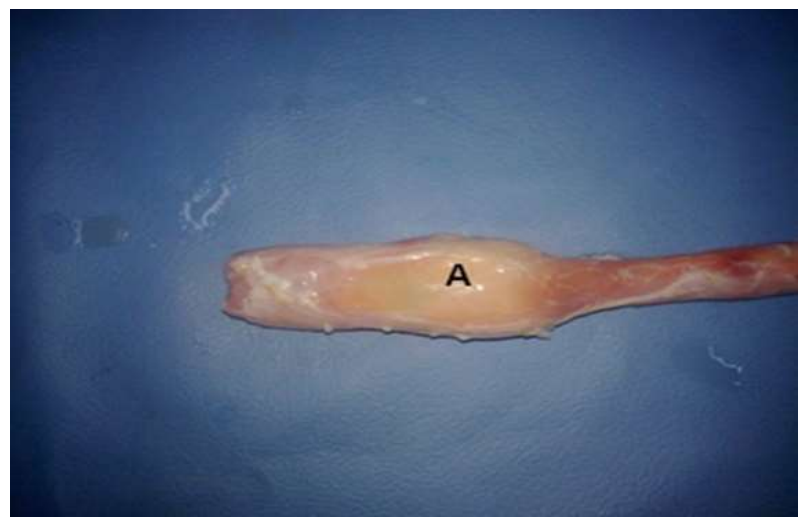

Figure 4: Ovine esophagus showing esophageal cylindrical diverticulosis (A). 


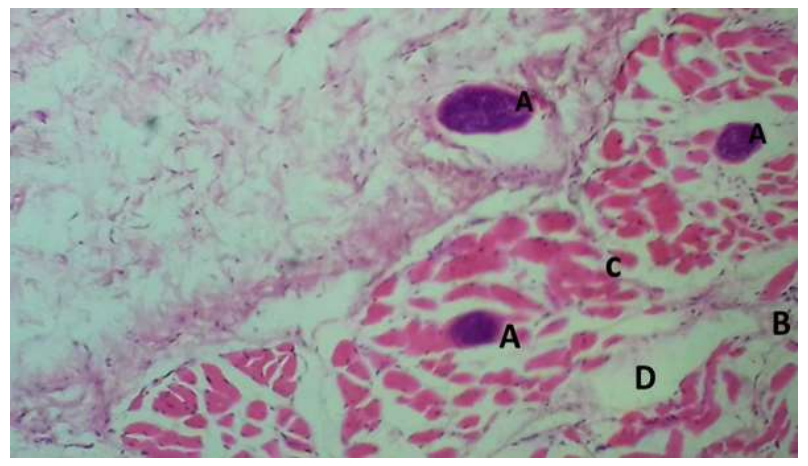

Figure 5: Photomicrograph of ovine esophagus section showing different stages of sarcosystosis in muscularis between muscle fibers (A), mild infiltrations of inflammatory cells (B), coagulative necrosis in myocytes (C), edema (D). H\&E, 180x.

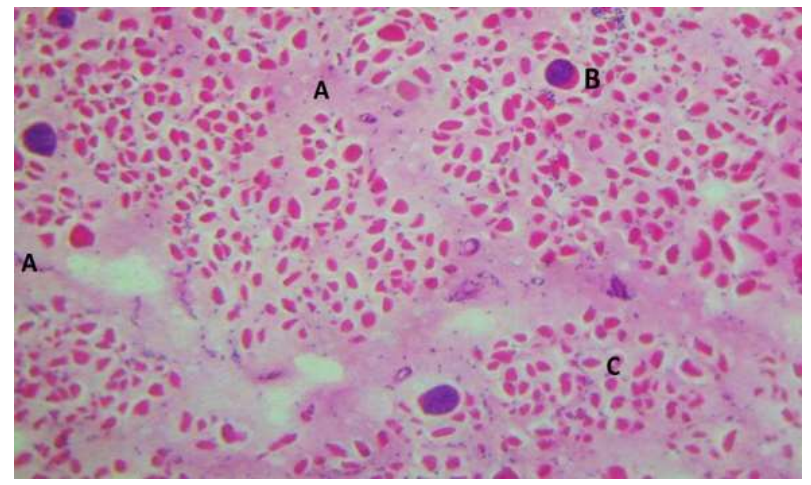

Figure 6: Photomicrograph of ovine esophagus section showing thickening of fibrous trabeculae between muscle fibers (A), parasite sarcocystis (B), with coagulative necrosis of muscle fibers $(C)$. H\&E, $165 x$.

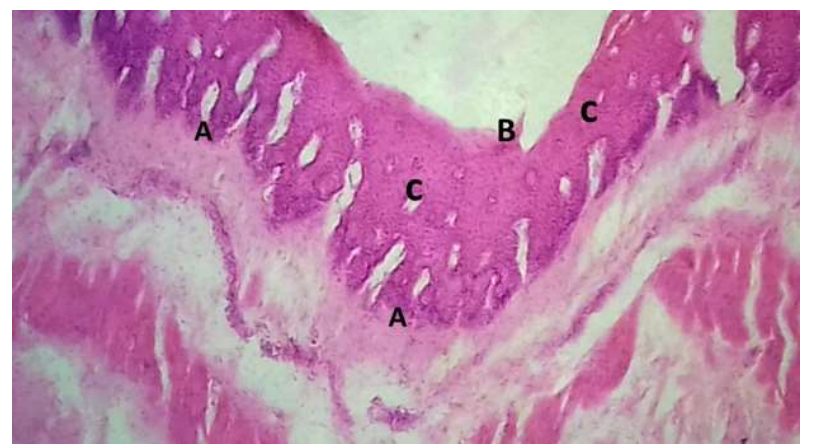

Figure 7: Photomicrograph of ovine esophagus section showing sever hyperkeratosis in epithelial cells lining the esophagus which extend as projection towered the mucosa (A), desquamation of epithelial lining the esophagus (B), with vacuolar degeneration (C). H\&E, 115x.

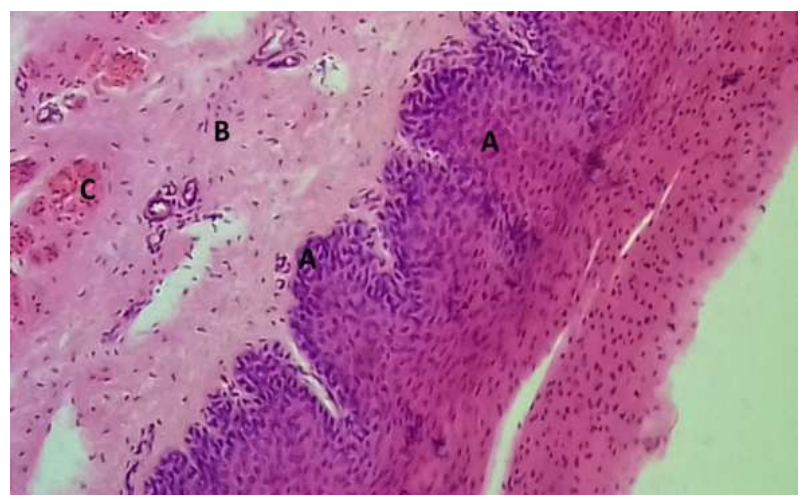

Figure 8: Photomicrograph of ovine esophagus section showing sever hyperkeratosis (A), fibrosis in sub mucosal layer (B), with hemorrhage (C). H\&E, 240x.

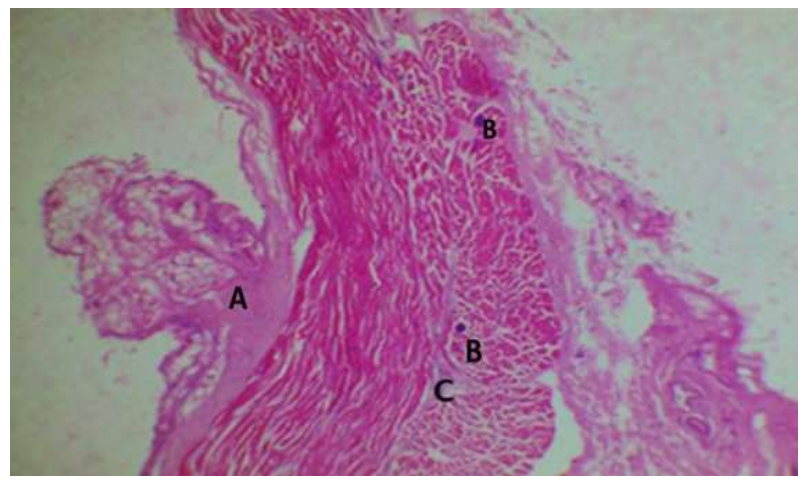

Figure 9: Photomicrograph of ovine esophagus section showing polypoid form projection of connective tissue extend to the lumen of esophagus (A), with different stages of parasite sarcosystosis in muscularis (B), fibrosis between bundles of muscle fibers (C). H\&E, 90x.

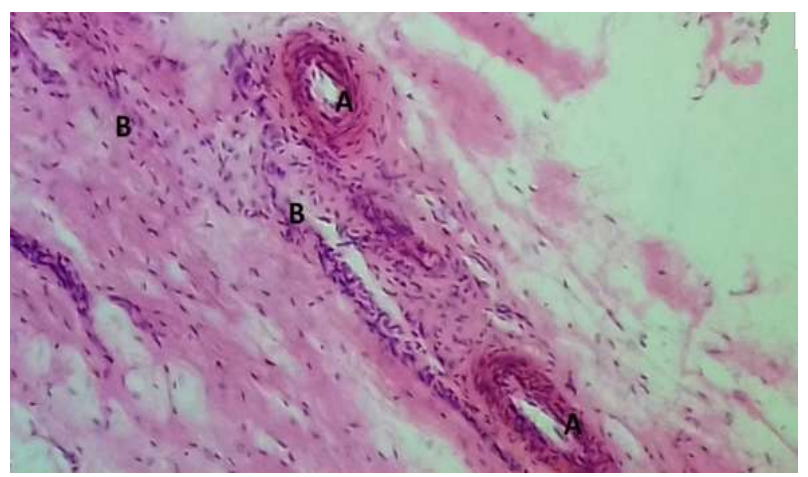

Figure 10: Photomicrograph of ovine esophagus section showing vasculitis and thickening in tunica media (A), with sever infiltrations of inflammatory cells (esophagitis) (B). H\&E, 240x. 


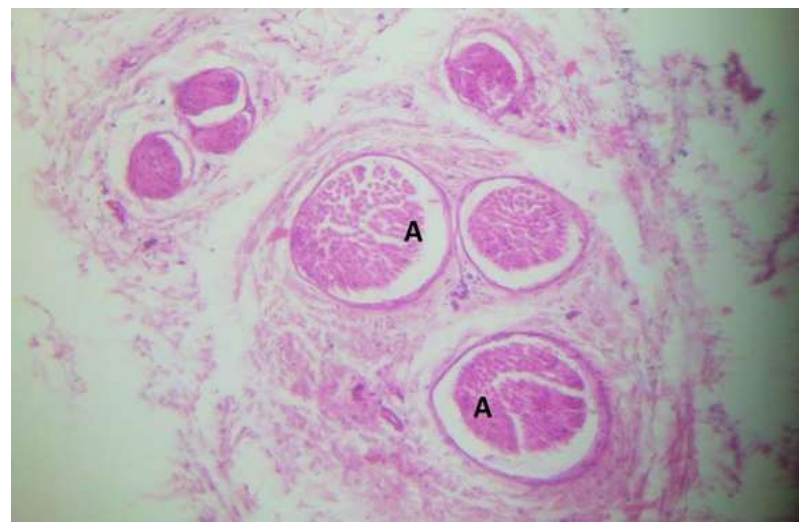

Figure 11: Photomicrograph of ovine esophagus section showing cross section of worms (nematodes) in mucosal layer (A). H\&E, 145x.

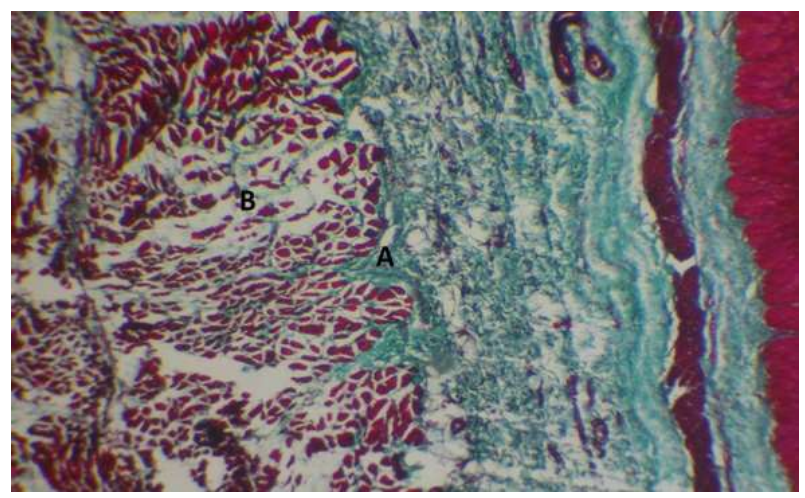

Figure 12: Photomicrograph of ovine esophagus section showing proliferation of collagenous fibers between bundles of muscle fibers which takes green color (A), edema between muscle bundles (B). Masson trichrome stain, 180x.

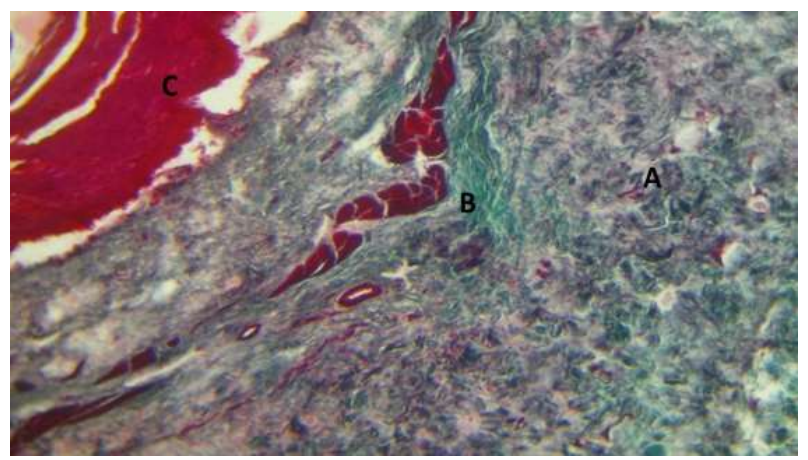

Figure 13: Photomicrograph of ovine esophagus section showing hyperplasia of connective tissue (A), deposition of collagen fibers takes bluish green color (B), with hyperkeratosis of epithelial cells takes red color (C). Masson trichrome stain, 180x.

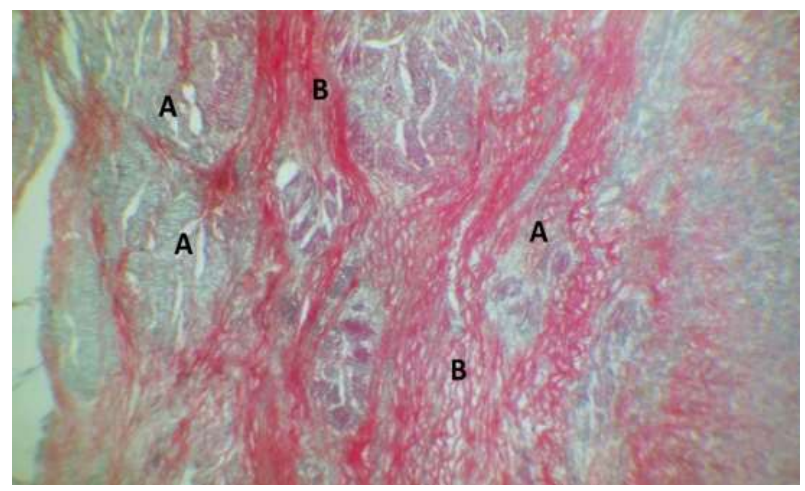

Figure 14: Photomicrograph of ovine esophagus section showing sever hyperplasia in sub mucosal layer of esophagus (A), with presence of keratin between proliferative layers which takes red color (B). Masson trichrome stain, 265x.

\section{Discussion}

The results of this study showed that coagulative necrosis scores the highest incidence rate among the esophageal lesions occur in acute infectious disease and sever toxemias as typhoid fever (10), also is associated with the nutritional deficiency in animal feed, the cause of this lesion is deficiency in vitamin $\mathrm{E}$ and selenium components, which are associated in function of preventing peroxidation of membrane of cell organelles and cell membrane, and the lack of these components cause white muscle disease in calves, as well as stiff lamb disease in small lambs this because the selenium is a natural components of glutathione peroxidase enzymes, a significant anti-oxidative stress, as feeding on rational stuffs with little nutritional value is not sufficient for the daily needs of the animal and the presence of some unsaturated fatty acids or fatty acids that interfere with the absorption processes or metabolic processes of these elements which leads to the breakdown of vitamin $\mathrm{E}$ $(11,12)$. The sloughing and desquamation of epithelial lining the esophagus caused by the continuous irritation this mostly accompanied by vacuolar degeneration it happens mainly due to infection with nematodes or hypoxia or infection with bacterial and viral agents (4). Hemorrhage occurred is due to slaughter or bruising during the transfer process as well as stress during the animal transport or slaughter, the presence of edema in some sections which occurs due to eosinophilic esophagitis. In some sections vasculitis was also observed with severe infiltration of inflammatory cells and thickening of the tunica media in the mucous layer of the esophagus this occur due to inflammation and presence of parasite sarcosystis also worms infestation (13).

The results of this study showed the presence of epithelial hyperplasia and fibroplasia which represented by 
the proliferation of fibrous tissue with hyperkeratosis which extends in the form nodules inside the esophageal lumen these lesion also happened due to irritation and inflammation caused the erosion of the epithelium as a result of worms infestation (6), vitamin A deficiency and zinc deficiency has a significant role also in the incidence of keratosis and parakeratosis with squamous cell hyperplasia (14), and the cause of hyperplasia is the presence of nematodes buried inside the stratum corium and the presence of these worms causes hyperkeratosis, acanthosis and eosinophilic esophagitis. Fibroblasts are stimulated through continuous irritation or through the presence of white blood cells especially eosinophil's which are responsible for remodeling of tissue through the secretion of growth factor TGF- $\beta$ and stimulates the proliferation of fibroblasts and the production of collagen and the occurrence of fibrosis $(15,16)$.

The reason for the occurrence of jaundice is liver failure and bacterial infection cause lysis of blood or blockage of bile ducts caused by hepatic worms or poisoning of copper and selenium, sheep are known to have high sensitivity to copper poisoning because the liver has high affinity to copper absorption so the excess amount of copper released to the blood stream lead to the destruction of red blood cells thus increase the concentration of bilirubin and the incidence of jaundice (17). Since the sheep in direct contact with the pastures and the external environment, the incidence of parasitic infestation with sarcosystis recorded in high percentage and there are 220 species of this parasite only four species affect sheep which is $S$. ovicans, $S$. tenella, S. medusiformis and S. gigantea the first one and second species are highly pathogenic to sheep $(18,19)$.

The high incidence of parasitic infestation in sheep may explain the chronic inflammatory response eosinophilic esophagitis which represented by infiltration of the inflammatory cells, especially eosinophil's and lymphocytes, between the bundles of muscle fibers this is match with $(4,20)$. When the cyst is ruptured sarcotoxin is released into the muscles and cause eosinophilic esophagitis, this type of inflammation occurs with severe infiltration of lymphocytes and plasma cells (21). The high incidence of this parasite leads to a sharp reduction in milk production and repeated abortion (22). Worms infestation happened leads to an inflammatory reaction around the worm which imbedded in the mucosa of esophagus cause eosinophilic myositis as well as hemorrhage, the presence of worm leads to a local inflammation in the epithelial layer with vacuolar degeneration and hyperkeratosis in the mucosal layer (23). A case of the esophageal diverticulum is a cylindrical or fusiform dilation in the esophagus either inherited or acquired is caused by deep esophageal inflammation or increased intra luminal pressure which leads to mucosal herniation (24).
The tissue sections stained with Masson trichrome showed presence of fibroplasia with collagen fibers, which is stained bluish green color, esophageal fibrosis occurs as a cause of cervical and thoracic trauma which involve the muscular layer finally this leads to recurrent esophageal obstruction or as a result of the continuous stimulation resulting from the presence of parasites sarcosystis and nematodes in the muscularis and subcutaneous layer this occur due to fibroplasia by stimulating fibroblasts which secrete chemical agents as transforming growth factor beta 1 (TGF- $\beta 1$ ) which stimulates the proliferation of fibroblasts and the production of collagen fibers (16).

\section{Conclusion}

It has been concluded from this study that the esophagus which is an important part of the digestive system affected with gross and histological lesions like hemorrhage, edema, sarcosystosis, nematodes, sloughing of epithelial lining the esophagus, fibroplasia, hyperkeratosis, eosinophilic inflammation, jaundice and diverticulosis.

\section{Acknowledgment}

I would like to thanks to all those who provided me the possibility to finished this article specially Department of Pathology and Poultry Diseases, College of Veterinary Medicine, University of Mosul.

\section{References}

1. Yasser YA, Atia AH, Salah A. Topographical anatomy of sheep. $1^{\text {st }}$ ed. Mosul: Dar Al-hikma; 1990. 188 p.

2. McGavin MD, Zachary JF. Pathologic basis of veterinary disease. $4^{\text {th }}$ ed. China: Mosby Elsevier; 2007. 408-412 p.

3. Eroschenko VP. Atlas of histology with functional correlations. $8^{\text {th }}$ ed. Canada: Mosby Elsevier; 1996. 171-182 p.

4. Al-Mallah K. Comparative pathological study of esophageal lesions in sheep and cattle slaughtered at Mosul slaughter house. Iraqi J Vet Sci. 2009;23(suppl 2):313-323. https://doi.org/10.33899/ijvs.2009.5692

5. Nascimento EM, Campos EM, Maia LA, Medeiros RT, De Alcantara MB, Vilar SD, Riet IF. Mega esophagus in sheep and goat. Ciencia Rural. 2016;46(8):1450-1455. https://doi.org/10.1590/0103$8478 \mathrm{cr} 20151414$

6. Varcasia A, Antonio S, Hiroshisato AA. First record of Gongylonema nepalensis in domestic and wild ruminants in Europe. Vet Parasitol. 2017;246:11-18. https://www.ncbi.nlm.nih.gov/pubmed/28969772

7. Tourchi M. Multiple effects of braken fern under in vivo and in vitro conditions. Asian Pac J Cancer Prev. 2014;15(18):7505-7513. https://doi.org/10.7314/apjcp.2014.15.18.7505

8. Al-Haaik AG. A gross anatomical and histological study of pancreas in adult Kestre. Iraqi $J$ Vet Med. 2019;33(2):175-180. https://doi.org/10.33899/ijvs.2019.162960

9. Luna LG. Manual of histological staining methods of the armed forces institute of pathology. $3^{\text {rd }}$ ed. New York: McGraw - Hill Book Company; 1968. 32-39,94-95 p.

10. Anil A. Forensic medicine and toxicology for homeopathy. $1^{\text {st }}$ ed. New Delhi: Avichal publishing company; 2016. 228 p. 
11. Mahmood AF, Arif MF, Sadq SM, Alhoby AA, Abdurahman SA. Effect of different levels of selenium on the carcass characteristics of karadi lambs. Iraqi J Vet Sci. 2018;32(1):41-48. 10.33899/ijvs.2018.153792

12. Fryer MJ. Rationale for clinical trials of selenium as an antioxidant for the treatment of the cardiomyopathy of Fried Reich's ataxia. Med Hypotheses. 2002;58(2):127-32. https://doi.org/10.1054/mehy.2001.1474

13. Li JP, Tobias V, Day AS, Leach S, Lemberg DA. Esophageal sub epithelial fibrosis and hyalinization are features of eosinophilic esophagitis. J Pediatr Gastroenterol Nutr. 2011;52(2):147-53. https://doi.org/10.1097/mpg.0b013e3181ef37a1

14. Eslami A, Ashrefihelan J, Vahedi A. Study in the prevalence of pathology of Gongylonema pulchrum (Gullet worm) of sheep from Iran. Global Vet. 2010;5(1):45-48.

15. Varcasia A, Antania S, Hisroshisato A. First record of Gongylinema nepalensis in domestic and wild ruminants in Europe. Vet Parasitol. 2017;246:11-18. https://www.ncbi.nlm.nih.gov/pubmed/28969772

16. Aceves SS, Ackerman SJ. Relationships between eosinophilic inflammation, tissue remodeling and fibrosis in eosinophilic esophagitis. Immunol Allergy Clin North Am. 2009;29(1):197-211. https://doi.org/10.1016/j.iac.2008.10.003

17. Hansen SL, Ashwell MS, Legleiter LR, Fry RS, Lloyd FJK, Spears JW. The addition of high manganese to a copper-deficient diet further depresses copper status and growth of cattle. British J Nutr. 2009;101:1068-1078. https://doi.org/10.1017/s0007114508057589.

18. Abdel-Baki A, Allam G, Sakran TH, El-Malah EL. Lambs Infected with UV-attenuated sporocysts of Sarcocystis ovicanis produced abnormal sarcocysts and induced protective immunity against a challenge infection. Korean J Parasitol. 2009;47(2):131-138. https://doi.org/10.3347/kjp.2009.47.2.131

19. Omer SA, Alzuraiq AA, Mohammed OM. Prevalence and molecular detection of Sarcocystis spp. infection in the dromedary camel (Camelus dromedarius) in Riyadh city, Saudi Arabia. Biomed Res. 2017;28(11):4962-4965.

https://www.alliedacademies.org/articles/prevalence-and-moleculardetection-of-sarcocystis-spp-infection-in-the-dromedary-camelcamelus-dromedarius-in-riyadh-city-saudi-ar.pdf

20. Ahmed AM, Elshraway N, Youssef AI. Survey on Sarcocystis in bovine carcasses slaughtered at the municipal abattoir of El-Kharga, Egypt. Vet World. 2016;9(12):1461-1465. https://doi.org/10.14202/vetworld.2016.1461-1465

21. Sykes JB, Dubey JP, Lindsay 11, Prato P, Lappin MR, Guo LT, Mizisin AP, Shelton GD. Sever myositis associated with sarcocystic spp infestation in dogs. J Vet Inter Med. 2011;25:1277-1283. https://doi.org/10.1111/j.1939-1676.2011.00828.x

22. Dehkordi ZS, Yalameha B, Sari AA. Prevalence of Sarcosystic infestation in processed meat products by using digestion and impression smear methods in Hamadan, Iran. Clin Pathol. 2017;26:1023-1026. https://doi.org/10.1007/s00580-017-2478-3

23. Kheirandish R, Radfar MH, Sharifi H, Mohammadyari N, Alidadi S. Prevalence and pathology of Gongylonema pulchrum in cattle slaughtered in Rudsar, northern Iran. Sci Parasitol. 2013;14(1):37-42. https://pdfs.semanticscholar.org/1 f04/6acc3913548fd960bb4d4d9bf3b 40f08057e.pdf

24. Penadés M, Guerrero I, Benito-Peña A, Corpa JM. Duodena gland cysts and pseudo diverticula in sheep. J Vet Diagn Invest. 2010;22(4):649-51. https://doi.org/10.1177/104063871002200428 